\title{
Estudo exploratório para implementação de um espaço maker
}

\author{
Exploratory study for the implementation of a maker space
}

\author{
Dstela Aparecida Oliveira Vieira \\ Pós doutoranda em Educação pela Universidade Federal de Lavras \\ UFLA - Minas Gerais - Brasil. \\ Doutora em Educação pela Aix Marseille Université em cotutela com a Universidade Federal de Minas Gerais \\ estelavieira1@ufla.br
}

\begin{abstract}
Ronei Ximenes Martins Doutor em Psicologia pela Universidade São Francisco - Professor do Departamento de Educação da Universidade Federal de Lavras;

Pro reitor de graduação UFLA - Minas Gerais - Brasil. rxmartins@ufla.br
\end{abstract}

Resumo: A era digital traz uma infinidade de possibilidades de acesso a informações e nos leva a questionar: como a escola se adaptará às novas demandas por aprendizado em um mundo tão rápido e desafiador? A partir deste questionamento, ao longo de dez meses um grupo de pesquisadores de uma universidade pública concebeu uma proposta de espaço maker (e-lab) para estudantes do ensino fundamental, como espaço de integração entre investigação e aprendizagem. Este relato tem por objetivo apresentar o trabalho de organização desse espaço e seus resultados preliminares. A metodologia aplicada para reunião dos dados foi a observação participante, bem como a utilização de cadernos de campo e atas de reuniões. Nas discussões, os elementos didáticos pedagógicos ressaltados foram: avaliação diagnóstica para planejar, organizar, acompanhar e avaliar atividades; atuação dos educadores em dois grupos: tutoria-coaching e tutoria-andaime com base na pedagogia por projetos e problematização; trabalho com a reciprocidade educativa a partir de valores éticos e respeito pelas diferenças, por exemplo, a diferença de idade. A criação do e-lab abrangeu aspectos técnicos, estruturais e didático-pedagógicos, mas como é proposta em implantação, será no curso da atividade, ou seja, na implementação e execução das atividades, que será possível avaliar e ajustar as metas.

Palavras-chave: Educação maker. Educação 4.0. Metodologias de aprendizagem. Ensino fundamental. Base Nacional Comum Curricular.

\begin{abstract}
The digital age brings a multitude of possibilities for accessing information and leads us to question: how will the school adapt to the new demands for learning in such a fast and challenging world? From this questioning, over a period of ten months a group of researchers from a public university conceived a proposal for a maker space (e-lab) for elementary school students, as a space for integration between research and learning. This report aims to present the work of organizing this space and its preliminary results. The methodology applied to gather the data was participant observation. Field notebooks and meeting minutes were used. In the discussions, the pedagogical didactic elements highlighted were: diagnostic evaluation to plan, organize, monitor and evaluate activities; performance of educators in two groups: tutoring-coaching and tutoring-scaffolding based on project pedagogy and problematization; work with educational reciprocity based on ethical values and respect for differences, for example, the age difference. The creation of the e-lab covered technical, structural and didactic-pedagogical aspects, but as it is proposal in implementation, it will be in the course of the activity, that is, in the implementation and execution of the activities, that it will be possible to evaluate and adjust the goals.
\end{abstract}

Keywords: Education maker. Education 4.0. Learning methodologies. Elementary education. Common National Curricular Base. 


\section{Introdução}

A ascendente presença das tecnologias digitais de informação e comunicação (TDIC) em nossas vidas não é novidade, no entanto, no Brasil ainda somos uma sociedade muito mais de consumo que de produção consciente destas tecnologias - havendo, ainda, dificuldades de capital humano para manipulação competente das mesmas. As TDIC trouxeram novas formas de relacionamento, trabalho e gerenciamento do tempo/espaço, o modus operandi e vivendi de hoje não é mais o mesmo de ontem. Esta revolução dos meios de produção de bens materiais e de consumo influencia o conhecimento, a formação e a preparação de nossos jovens para a vida.

Segundo os dados da World Competitiveness Yearbook de 2019, um relatório anual sobre a competitividade dos países, em 2008 o Brasil ocupava a 57ª posição (IMD, 2019). O relatório é produzido a partir da capacidade do país de ofertar tecnologias digitais, adotar, desenvolver e explorar e também sua aplicação em negócios e em práticas administrativas e gerenciais. Os dados, produzidos em parceria com o Núcleo de Inovação e Empreendedorismo da Fundação Dom Cabral são elaborado a partir de 50 variáveis que se agrupam em três fatores: grau de geração e absorção de conhecimento; desenvolvimento e uso de novas tecnologias; e atitudes e práticas para aproveitar o futuro. As TDIC estão em uma espiral de evolução que o que é novo hoje, amanhã já se torna obsoleto, e para lidarmos com este conjunto de tecnologias na educação precisamos nos preparar com maior efetividade. Diante disso, este estudo se propõe a uma reflexão sobre o saber fazer do ensino-aprendizagem na educação 4.0 com vistas a avançarmos para a educação $5.0^{1}$.

As atividades e meios de produção capitalista se automatizam cada vez mais, com novos tipos de robôs, recursos da Internet das Coisas, Inteligência Artificial e Linguagem Computacional. Em consonância com este processo, mas também para fazer oposição crítica aos seus efeitos indesejados, surgiram o movimento maker, os maker Labs ou Laboratórios de Fabricação, FabLabs, que são espaços de aprendizagem, pesquisa, inovação e invenção que buscam mostrar que qualquer pessoa em qualquer lugar pode fazer qualquer coisa. As metodologias utilizadas nestes espaços são centradas no estudante, buscam promover ações diferenciadas, interdisciplinares e desenvolver projetos "mãos na massa" fundamentados em situações-problema para que o estudante possa refletir sobre, buscar soluções inovadoras que respondam à demanda de uma sociedade ética e democrática.

\footnotetext{
${ }^{1}$ Educação 3.0 surge com as tecnologias digitais. Este modelo possibilita a customização dos conteúdos e metodologias buscando maior engajamento dos estudantes. A Educação 4.0 tem como base a indústria 4.0 e busca ensinar linguagem computacional, inteligência artificial, robótica e a Internet das Coisas, a construção e o uso de bancos de dados. A Educação 5.0 aborda o tema tecnologia para além das habilidades específicas demandada pelo mercado, visa também habilidades cognitivas, consciência socioambiental e empatia.
} 
A ideia dos fabLabs é que as atividades sejam desenvolvidas a partir do interesse dos próprios estudantes, com o estímulo à pesquisa e ao pensamento reflexivo. E, a partir destes eixos, sejam propostas novas soluções para problemas simples e complexos que possibilitem descobrir, conectar, criar, refletir e se necessário repensar formas diferentes de solução. Tal perspectiva encontra ressonância teórica com Jerome Bruner e Vygotsky que propõe a aprendizagem a partir do universo simbólico e os signos, respectivamente, em relação com o contexto sócio cultural. Este tipo de atividade visa instigar o estudante a realizar seus projetos e descobertas, para que assim possa fortalecer suas competências e desenvolver novos conhecimentos. Sendo importante destacar que ela parte do pressuposto de que o desenvolvimento crítico, ético e emancipatório do estudante é para além das tecnologias digitais.

No entanto,a partir da observação do relatório da World Competitiveness Yearbook de 2019 vemos que o Brasil se encontra em uma posição desfavorável. Ainda a pouco tínhamos a visão de que os "nativos digitais", jovens que nasceram imersos na tecnologia digital, dominariam as tecnologias, uma vez que esta faz parte da sua vida cotidiana. Porém estudos mais recentes, como o da ECDL Foundation (2016), apontam que mesmo com habilidades tecnológicas estes jovens na maioria dos casos fazem uso de tais intuitivamente e não de forma segura e eficaz, ou seja, há uma discussão sobre a competência de uso da tecnologia digital por esses jovens.

Estas questões nos trazem inquietação sobre a preparação de nossas futuras gerações para atuar no mundo do trabalho que a quarta revolução industrial gerará. Se de um lado a mudança no trabalho e nos meios de produção impõem novas competências, por outro oferece um grande número de oportunidades para profissionais inovadores e criativos. E aos profissionais da área da educação cabe pensar estratégias que desenvolvam as competências digitais de nossos estudantes para que, para além de suas habilidades, estes possam fazer uso competente e crítico das novas tecnologias.

A formação dos nossos estudantes é assegurada na Lei de Diretrizes e Bases da Educação Nacional instituída em 1996 (BRASIL, 1996), que propõe um currículo único para toda nação, na busca de que as escolas garantam uma fundamentação comum de aprendizagens a todos. Há algum tempo esta discussão vem sendo estabelecida e, a partir de um longo período de discussão, em 2017 foi aprovada a Base Nacional Comum Curricular (BNCC) em vigência. A BNCC (2017) possui caráter normativo e tem por objetivo definir o conteúdo básico a ser ensinado a cada um dos segmentos da educação escolar, pública ou privada, assegurando assim ao estudante seus direitos de aprendizagem e desenvolvimento, em conformidade com o que preceitua o Plano

2 PRENSKY, Marc. Digital natives, digital immigrants part 1. On the horizon, v. 9, n. 5, p. 1-6, 2001. 
Nacional de Educação (PNE). Deste modo foram definidas dez competências gerais que se interrelacionam - ou direitos de aprendizagem - partindo de sua definição como "a mobilização de conhecimentos (conceitos e procedimentos), habilidades (práticas, cognitivas e socioemocionais), atitudes e valores para resolver demandas complexas da vida cotidiana, do pleno exercício da cidadania e do mundo do trabalho (BNCC, 2017, p. 8)".

Dentre as dez competências propostas, a quinta se refere às Tecnologias Digitais de Informação e Comunicação (TDIC) que propõe que ela perpasse todo o currículo de maneira transversal. Nela é assinalada a necessidade de ser desenvolvida de "forma crítica, significativa, reflexiva e ética nas diversas práticas sociais” (BNCC, 2017, p.9) o que comunga com as projeções de mercado da indústria 4.0 e a Educação 4.0.

A aprendizagem ativa contida na Educação 4.0 propicia aos estudantes a experiência da aquisição e aprimoramento de competências e habilidades via tecnologias, e acontece em espaços makers - estes são espaços de criação, laboratórios ou oficinas - nos quais pessoas de diversas áreas trocam conhecimento e experiência para construir algo em conjunto. Esses espaços oferecem condições aos seus usuários para a experimentação do tipo Do-It-Yourself (DIY), visando a criação de projetos, protótipos e produtos inovadores associados ao uso de tecnologias.

A temática maker, educação mão na massa, foi discutida pelo grupo de pesquisadores e estudantes que compõem o Laboratório de Práticas Pedagógicas Inovadoras (LPPI) do Departamento de Educação da Universidade Federal de Lavras (UFLA), que pensaram estratégias para aprofundar o tema e subsidiar o preparo de futuros professores nesta temática. Procuramos, então, trabalhar de forma coletiva na construção de um espaço de formação que pudesse produzir e disseminar o conhecimento científico e tecnológico, contribuir para formação humana e profissional criativa comprometida com a ética e por consequência, a construção de uma sociedade mais justa e democrática. A proposta do e-Lab UFLA (espaço lab Ufla) é desenvolver um projeto maker, interdisciplinar e com metodologias centradas no estudante do ensino fundamental, e estudar estratégias e recursos para implementação da "competência número cinco" da BNCC.

Falamos de um espaço de produção do conhecimento e formação voltado para as novas TDIC como mediadoras da aprendizagem e suas possibilidades de inovação e potencialidades. Portanto, acreditamos que este espaço deva permitir agregar conhecimento tecnológico, pedagógico e de conteúdos diferenciados, bem como oferecer a oportunidade de desenvolver tecnologias de ensino e aprendizagem alicerçadas na educação 4.0. Para que isso ocorra as metodologias buscadas são mais interativas, com vistas no desenvolvimento crítico, ético e

\footnotetext{
${ }^{3}$ Faça você mesmo.
} 
emancipatório do estudante para que se possa contribuir com a constante exigência de desenvolvimento de novas habilidades e conhecimentos para além das tecnologias digitais. Este artigo, elaborado a partir da observação participante, objetiva apresentar a proposta inicial do projeto de intervenção maker destinada a estudantes do ensino fundamental, bem como os resultados preliminares.

\section{Fundamentação teórica}

A era digital traz acesso a uma infinidade de informações bem na palma de nossas mãos e em segundos. Moran (2017, p. 17) coloca a seguinte questão: Como a escola pode tornar-se relevante para o aprendizado em um mundo tão rápido e desafiador? Para além da formação de capital humano, a educação tem o propósito de socializar o indivíduo, prepará-lo para vida em sociedade de forma autônoma para que possa elaborar suas decisões de forma criativa e ética. Para o autor isso será possível se implementarmos outro modelo escolar, mais flexível e centrado no aluno, com aprendizagem mais significativa, metodologias ativas e uso das tecnologias digitais.

Com base nessas mudanças o poder público propõe a BNCC com o objetivo de formar estudantes com conhecimentos e habilidades essenciais para o desenvolvimento da sociedade do século XXI. Esses conhecimentos são apresentados em formato de competências gerais, consolidadas em direitos de aprendizagem e desenvolvimento. A competência Digital foi inserida da seguinte forma:

[...] ao final da educação básica o estudante deverá compreender, utilizar e criar tecnologias digitais de informação e comunicação de forma crítica, significativa, reflexiva e ética nas diversas práticas sociais para se comunicar, acessar e disseminar informações, produzir conhecimentos, resolver problemas e exercer protagonismo e autoria na vida pessoal e coletiva (BRASIL, 2017, p. 9).

O texto ainda acrescenta que a partir da cultura digital "a escola pode instituir novos modos de promover a aprendizagem, a interação e o compartilhamento de significados entre professores e estudantes" (p. 59). A BNCC aponta a necessidade de se abordar novos letramentos, multiletramentos, sejam estes lineares ou hipertextuais, destinados a formar designers - "alguém que toma algo que já existe (inclusive textos escritos), mescla, remixa, transforma, redistribui, produzindo novos sentidos, processo que alguns autores associam à criatividade” (p. 68).

É importante apontarmos aqui que a discussão sobre o ensino por competências apresenta alguns dilemas. O texto de Ricardo (2010) traz estas controvérsias e apresenta diferentes visões sobre o tema. Podemos citar, por exemplo, a explicação da competência como "qualificação 
acrescida de um saber-fazer". Outro exemplo, em oposição à visão anterior, seria a de que a intenção do ensino por competências é assegurar a adesão dos alunos ao projeto escolar uma vez que o acesso à informação e ao conhecimento por si só não resolve o problema das desigualdades e heterogeneidades presentes no contexto escolar. Se reduzirmos competência a lógica de mercado o e/ou à perspectiva da formação para o trabalho, o ser humano seria um mero recurso, passando de sujeito a objeto do capital moderno, e ao pautar a organização dos currículos e dos programas escolares em competências seria atribuído um sentido prático aos saberes escolares e abertura para o mundo econômico, privilegiando a prática em detrimento do conteúdo. Portanto, a abordagem de competência tem que se dar a partir de referenciais que contemplam os aspectos cognitivos do saber-fazer, não a reduzindo à compreensão de formação de mão-de-obra.

A partir desta constatação, buscamos adotar o conceito de competência proposto por Perrenoud (2002). Para chegar ao seu conceito de competência Perrenoud se apropria de vários conceitos da didática das ciências da escola francesa. Para o autor, a competência não é a aplicação de conhecimentos memorizados, mas de valores, de julgamentos, discernimento e análise dos recursos disponíveis. Dito de outra maneira, aprender por competências não se resume a simples execução de uma tarefa sem mobilizar conhecimentos mais complexos, saberes incorporados ao longo de um trabalho intelectual. O autor propõe que sejam utilizados nas práticas instrumentos que possibilitem atividades analíticas, a partir da elaboração de problemas e estratégias originais mobilizando os recursos cognitivos do estudante para resolvê-los.

Perrenoud (1999) deixa claro que a mobilização ${ }^{4}$ dos recursos cognitivos no processo de aprendizagem não é uma estratégia simples, ao contrário, ainda é de difícil compreensão e engloba a reconstrução constante do conhecimento, principalmente em situações complexas. Para tal, é necessário a mobilização de recursos, experiências, saberes e objetivos do sujeito para que a competência se concretize. Assim, para o autor, a divergência no entendimento do conceito de competência se encontra na crença de que ao se desenvolver competências, os conhecimentos não são mais transmitidos. No entanto, podemos falar em ação humana sem qualquer tipo de conhecimento? Perrenoud (p.6) completa "Quanto mais complexas, abstratas, mediatizadas por tecnologias, apoiadas em modelos sistêmicos da realidade forem consideradas as ações, mais conhecimentos aprofundados, avançados, organizados e confiáveis elas exigem”.

Por conseguinte, a compreensão e a análise da prática possibilitarão ao longo do tempo orientações e objetivos mais complexos, o que comunga com a concepção de competência proposta na BNCC. Assim, alicerçados na BNCC, a Sociedade Brasileira de Computação (SBC)

${ }^{4}$ Perrenoud prefere o termo mobilização ao termo transmissão. 
propôs diretrizes para ensino de Computação na Educação Básica fundamentadas no Pensamento Computacional e a compreensão do Mundo Digital. A proposta é que a partir do uso das ferramentas oferecidas pelo mundo da tecnologia digital se possa fortalecer a dinâmica da comunicação e informação, dando poder de opinião a todo membro da sociedade com base em três eixos: Pensamento Computacional, Mundo Digital e Cultura Digital. A SBC conceitua estes três eixos da seguinte maneira:

\begin{abstract}
Pensamento Computacional se refere à capacidade de compreender, definir, modelar, comparar, solucionar, automatizar e analisar problemas (e soluções) de forma metódica e sistemática, através da construção de algoritmos. [...] A compreensão do mundo digital é importante para que o estudante possa se apropriar dos processos que ocorrem no mundo digital, podendo compreender e criticar tendências, sendo ativo neste cenário. Para uma compreensão estruturada do mundo digital, e não apenas efêmera e permeada de tecnologias, identificam-se 3 pilares principais, chamados codificação, processamento e distribuição. [...] A Cultura Digital [...] aqui chamada de [...] letramento em tecnologias digitais, [...] análise dos novos padrões de comportamento e novos questionamentos morais e éticos na sociedade que surgiram em decorrência do Mundo Digital. A Cultura Digital compreende as relações interdisciplinares da Computação com outras áreas do conhecimento, buscando promover a fluência no uso do conhecimento computacional para expressão de soluções e manifestações culturais de forma contextualizada e crítica (SBC, 2019, p.5).
\end{abstract}

As competências específicas a serem desenvolvidas a partir do pensamento computacional ao longo do Ensino Fundamental são chamadas na BNCC de Cultura Digital, sendo um eixo transversal e interdisciplinar. A SBC apresentou as competências específicas da computação e as correlacionou com as competências da BNCC.

Figura 1 - Conceitos do eixo Pensamento Computacional no Ensino Fundamental

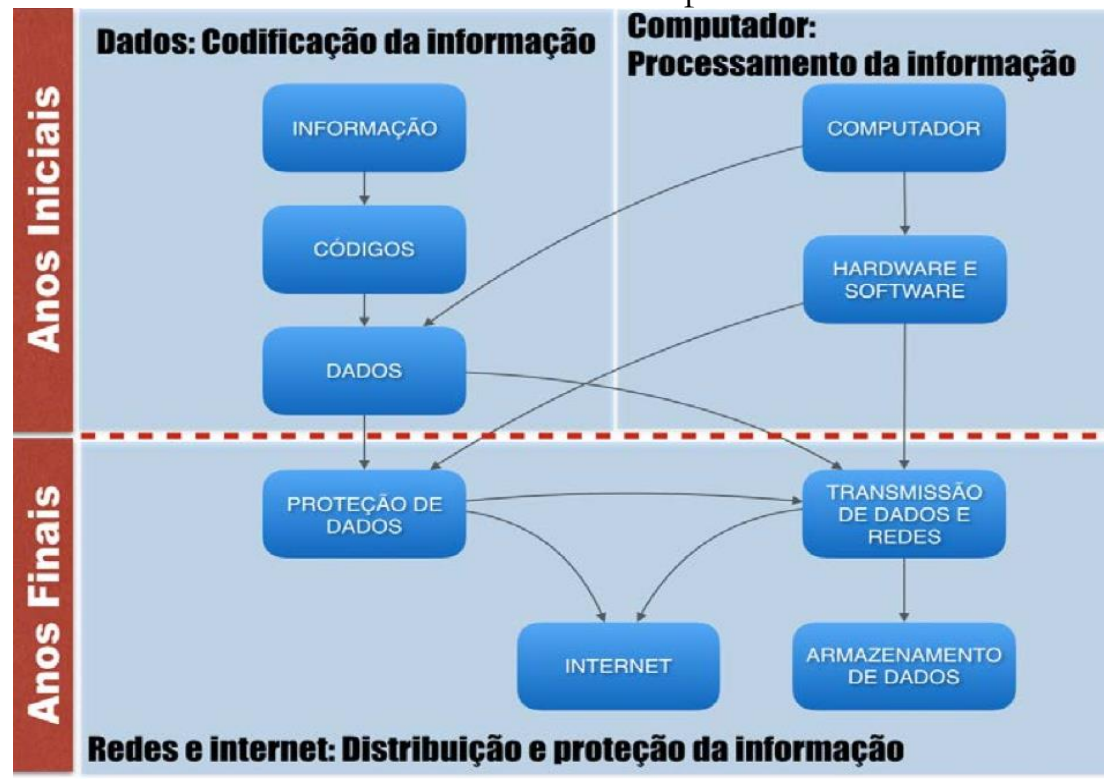

Fonte: Sociedade Brasileira Computacional (2019, p. 7). 
A proposta visa que nos anos iniciais sejam trabalhados conceitos de informação e comunicação relacionados às estruturas abstratas, se apropriem dos conhecimentos básicos para solução de problemas, fundamentados na lógica e em algoritmos e que demandem conhecimentos iniciais de aritmética. Os conceitos deverão ser apreendidos com base em experiências concretas e posteriores abstrações computacionais.

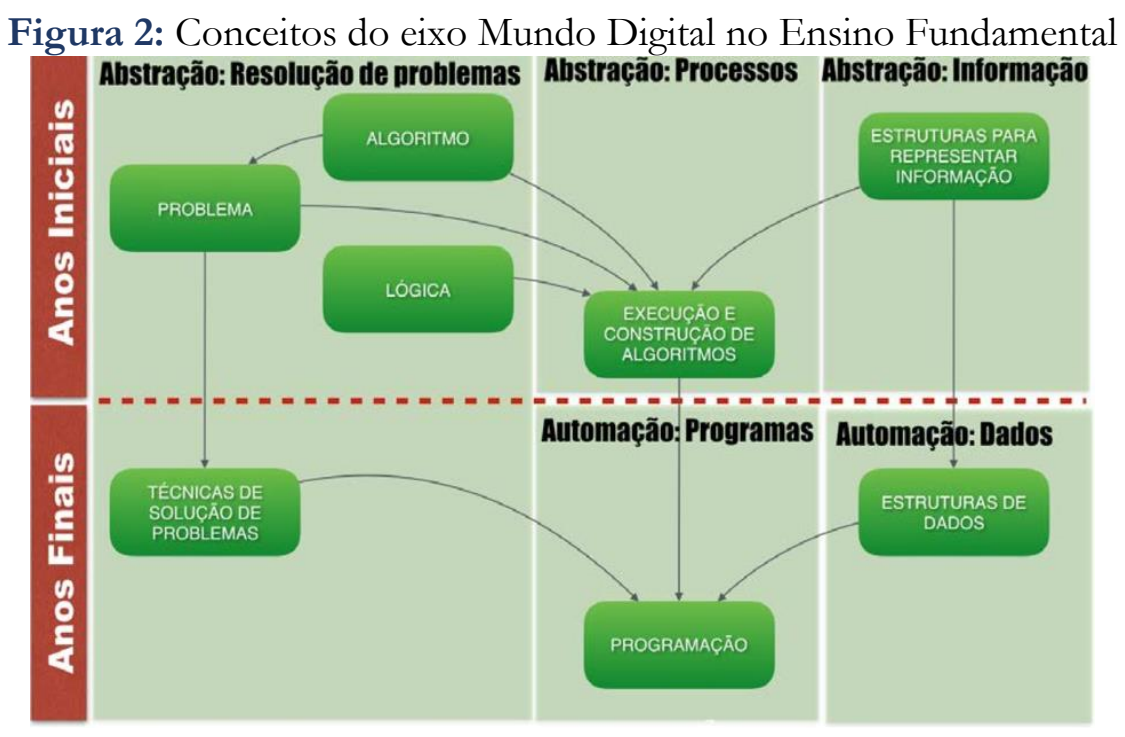

Fonte: Sociedade Brasileira Computacional (2019, p. 7).

Na segunda etapa do ensino fundamental os estudantes devem ser capazes de desenvolver soluções algorítmicas e resoluções de problemas em linguagem computacional e construir modelos computacionais. Apresentados desta maneira são apenas conceitos a serem trabalhados, no entanto, para serem desenvolvidas as competências necessárias, estes conceitos devem ser transpostos para o contexto da práxis. A transposição didática (CHEVALLARD, 1994), de forma resumida, se refere ao conjunto de conversões necessárias que a teoria, ou savoir savant, é submetida para que possa ser ensinada, savoir enseigné.

Para Chevallard (1982) o sistema didático é aberto e deve estar em consonância com seu ambiente, com o projeto social que o justifica. No entanto, o conhecimento produzido pela transposição didática não deve ser separado de suas origens e de sua produção histórica na esfera do conhecimento acadêmico, pois isso implicaria em um processo de naturalização. Apresenta-se assim um confronto entre o saber teórico e o saber a ser ensinado. Para além da transposição, para que o conhecimento seja apreendido é necessário que se estabeleça a mediação entre conteúdo, atividade e pessoas envolvidas. Para estabelecer esta leitura do projeto a mediação das atividades terá em sua base teórica dois autores: Vygotsky e Bruner. A justificativa desta escolha está no diálogo estabelecido por Bruner ao desenvolver sua teoria de aprendizagem e a proposta de uma 
aprendizagem em espiral que se complexifica conforme se estabelece o desenvolvimento e a aprendizagem do sujeito.

Vygotsky considera que a aprendizagem precede o desenvolvimento da criança em duas fases: o nível atual e o desenvolvimento que corresponde ao que a criança sabe fazer sozinha, o que se pode relacionar à capacidade de crianças mobilizarem seu senso comum para transformar em um saber científico, e o nível de desenvolvimento potencial, que a criança pode desenvolver com a ajuda de outra pessoa. Falamos do movimento passível de se estabelecer entre conceitos cotidianos e científicos propostos pelo autor. Quando o conceito científico (representação racional que a história lista) é transformado, se preenchendo de significado concreto (objetificação e ancoragem) e quando o conceito cotidiano é racionalizado pelas ações do pensamento de senso comum, o conceito é adquirido. O intermediário é a área de desenvolvimento proximal onde ocorre a aprendizagem. Esse espaço é sustentado como parte de um aprendizado que é construído entre um mediador e um aprendiz que não pode fazer tudo sozinho. E isto é realizado no contexto das experiências sociais experimentadas pelo aprendiz que amadurece e evolui (CARLOS, 2015).

Para Vygotsky, há uma diferença entre aprendizado e desenvolvimento. Para esse autor, o desenvolvimento advém de um aprendizado bem organizado, no qual é acionado vários processos de desenvolvimento que, de outro modo, seriam impossíveis de produzir. O desenvolvimento é mais lento que o aprendizado. Quando o estudante domina uma ação, ele inicia o processo de desenvolvimento que depende de vários outros fatores para se materializar. Assim, a palavra proximal não significa que o aprendizado necessariamente segue, mas é possível, é "iminente". As interações estabelecidas entre o indivíduo e seu ambiente podem permitir a maturação desse processo. Podemos encontrar diferentes níveis de maturidade, resultando em diferentes níveis de percepção e desenvolvimento (PRESTES, 2010) que serão acionados para que o aprendizado se concretize.

O desenvolvimento começa com um estímulo externo reconhecível pelo sujeito, ou seja, deve ter um significado para ser apreendido e internalizado. Para fazer isso, em um desenvolvimento real, Vygotsky defende que a ação externa seja obrigatória. É através de um processo de interação social entre os pares, professores e o mundo, que o desenvolvimento é possível. Mas não é certo que o desenvolvimento, que é iminente, aconteça. Ele está ligado a vários outros fatores. Esse processo, de acordo com Vygotsky, é socialmente construído. Assim, funções mentais superiores - atenção voluntária, memória, pensamento lógico verbal e conceitual, emoções complexas, etc. - se desenvolvem em interação entre si, isto é, em um processo de mediação. Essa mediação é feita usando instrumentos psicológicos criados socialmente (VYGOTSKY; LURIA, 1996). 
O segundo autor, Bruner (1985), associa o conceito de competência ao saber-fazer e este ao sentido de inteligência operativa, associa o saber mais ao "saber como" do que ao "saber que". Seu conceito de ensino é construído gradualmente, chamado de andaime, no qual ele "especifica" a natureza da "ajuda" proposta por Vygotsky em 1934, como a teoria da ZDP. A proposta de Bruner visa atuar nos aspectos emocionais e cognitivos, também enfatiza o interesse das "formas", que moldam as interações. Assim, rituais (ritual de adormecer, ritual da história contada, cálculo mental no início do dia na escola, etc.) são facilitadores por causa de seus efeitos estruturadores e reguladores. Ele argumenta que "a cultura dá forma à mente" e que precisamos entrar em uma cultura para entender as questões que estão por trás das situações de aprendizagem. Desta forma, o autor se junta ao campo daqueles que atribuem grande importância à socialização, o que o distingue consideravelmente dos cognitivistas clássicos.

Portanto, a elaboração da proposta de um espaço maker e os estudos a serem realizados no grupo têm sua fundamentação teórica alicerçada na transposição didática de Chevallard, no entendimento de competência proposto por Perrenoud e no diálogo estabelecido por Bruner com a obra de Vygotsky.

\section{Metodologia}

A partir da própria lógica da proposta maker os educadores, estudantes da universidade em questão, selecionados por edital para participarem do projeto, iniciaram suas atividades de formação interna compartilhando suas experiências entre si, fortalecendo suas habilidades e competências tecnológicas ao longo de dez meses. A proposta pedagógica do curso foi elaborada a partir das reuniões realizadas ao longo do período citado e sintetizadas para que a proposta de intervenção fosse concebida. Esse formato delineou a própria metodologia de pesquisa do estudo: observação participante.

Segundo Lakatos e Marconi (2013) na observação participante o pesquisador se torna um membro do grupo para que ele possa vivenciar a atividade. Há uma grande dificuldade para a objetividade ser mantida nesta técnica, pois elementos subjetivos exercem grande influência sobre o pesquisador. A observação natural, na qual o observador pertence ao grupo que investiga, possui a vantagem de permitir o acesso a uma ampla variedade de fenômenos e também limita, pois, os fatos acontecem de forma espontânea, não podendo ser previsto antecipadamente, sendo importante o uso dos instrumentos de registro durante as observações. Para tanto, além das atas das reuniões do projeto, foi utilizado um diário de campo para registro das atividades. 
Organizamos este relato na perspectiva de um estudo descritivo-exploratório, uma vez que ele busca explicitar o percurso efetivado pelo grupo na estruturação do projeto para introduzir competências computacionais por meio de um espaço maker. A escolha desta metodologia se justifica pela possibilidade de observar, acompanhar e organizar as propostas elaboradas no próprio contexto do projeto, o que permitiu uma análise indutiva e compreensiva da proposta a partir do olhar dos participantes (MÓNICO et al., 2017). Os critérios prévios para observação foram os elementos que se apresentaram como potenciais dados para organização do curso de formação de estudantes makers do ensino fundamental.

\section{Discussão e análise dos dados}

Diante da mediação por tecnológicas que perpassa nossas vidas, das atividades mais sutis até as mais complexas, como é o caso da educação, a equipe e-lab UFLA se propôs a estudar o livro "a modernidade líquida" de Bauman (2001). Isso porque o mundo das tecnologias digitais traz relações sociais mais efêmeras, o que Bauman intitula de modernidade líquida, fluida. Esta perspectiva do autor nos chamou a atenção, pois, ao mesmo tempo que a universidade traz em si os saberes acumulados ao longo dos séculos, ela também deve lidar com o novo, com o futuro. A final este é o papel da universidade, olhar para o futuro apoiada nas experiências sedimentadas em bases epistêmicas. A partir dessas discussões, paulatinamente o projeto foi desenhado pela equipe, em encontros realizados ao longo de dez meses, iniciados em maio de 2018, e ao final do último mês foram realizadas 4 oficinas com encontros semanais de duas horas, totalizando 8 horas de formação para sistematização das ideias.

A proposta central foi aproveitar as habilidades e competências de cada participante e transformá-las em saberes sistematizados. O resultado desta etapa foi a produção de vídeos de mobilização (temos que abandonar o conceito de aula) e a proposta de construção de um e-book para dar subsídios a cursos a serem realizados tendo como público a comunidade em geral, além de oficinas voltadas para estudantes do ensino fundamental I e II, foco deste relato.

A partir da produção de ideias ocorridas, discussões finais da etapa de estudos e de produção de materiais, foi pensado um curso orientado pela perspectiva Maker. Do processo de observação participante das atividades foi possível elencar oito polos - no sentido de atraírem ideias que se complementam-, sendo eles: público alvo, conteúdo programático, abordagem pedagógica, carga horária, estrutura de organização e recursos didáticos, competência requerida e a ser desenvolvida na equipe, competência a ser desenvolvida nos estudantes e divulgação e inscrição. 
A decisão sobre qual seria o público-alvo da primeira iniciativa de mobilização para competências maker por meio de um curso foi elemento contraditório nas discussões. Era certo que ele seria o infanto-juvenil, no entanto, estabelecer a faixa etária foi o elemento fundamental do diálogo, visto que a equipe se sentia insegura para trabalhar com o ensino fundamental I, mas ao mesmo tempo a equipe também contava com futuros pedagogos além de estudantes de outras áreas, como exatas e saúde. Deste modo, optou-se por trabalhar com 20 estudantes do fundamental I e 20 estudantes do fundamental II.

À medida que a discussão amadureceu, os elementos da proposta pedagógica tomavam corpo. Foram assinalados subsídios importantes da abordagem pedagógica a ser trabalhada, a equipe destacou a relevância de ser feita a sondagem com as crianças - saber o que gostam, a expectativa em relação ao curso e o conhecimento prévio sobre o tema - para ser montada uma proposta mais individualizada. Para partir de um ponto em comum e ser realizado o acompanhamento da turma, foi pactuado a apresentação de um menu de ofertas. A intenção é apresentar aos estudantes possibilidades de escolha e incentivar o potencial da criança e a possibilidade de um ensino personalizado e a formação de um maker ${ }^{5}$. Para que isso seja viável foi proposto o seguinte processo de tutoria: um membro da equipe ser responsável por 5 estudantes, independente do projeto escolhido e por aleatoriedade. Seria um tutor coaching ${ }^{6}$, com o objetivo de acompanhar individualmente o desenvolvimento dos estudantes sob sua responsabilidade.

Quanto à faixa etária, ficou estabelecido que essa não seria elemento para divisão dos grupos, uma vez que a equipe se propõe a trabalhar a reciprocidade educativa a partir de valores éticos como respeito pelas diferenças - sendo a faixa etária um elemento importante para serem trabalhadas a troca de saberes e experiências e a cordialidade. Assim, ficou estabelecido que o espaço Maker trabalharia com a pedagogia por projetos e a aprendizagem baseada em problemas (ABP ou $\left.\mathrm{PBL}^{\top}\right)$.

Em relação ao conteúdo programático, o conteúdo em si partiu de cada membro da equipe, de suas competências e conhecimentos prévios. No entanto, pensar em como ele seria disposto de maneira que trouxesse inovação foi possível apenas após o delineamento inicial da proposta pedagógica. Uma vez pactuado que a abordagem pedagógica seria por projetos e PBL foi possível

\footnotetext{
${ }^{5}$ Maker, palavra inglesa que significa fabricante, criador, construtor, autor. Apesar do movimento maker ser fortemente atrelado a projetos de eletrônica e robótica, a ideia engloba qualquer tipo de produto, assim um maker é aquele que cria, conserta e modifica objetos e produtos com suas próprias mãos.

${ }^{6} \mathrm{O}$ coaching é um tipo de acompanhamento realizado por um profissional específico, para cada área, que gerencia situações visando a melhoria de características pessoais para que a pessoa acompanhada ultrapasse o obstáculo e se emancipe. GUILLEMOT, Valérie; VIAL, Michel. Formation au coaching: Quelle place émergente pour les Sciences de l'Education. Les Cahiers du CERFEE, Recherches émergentes en éducation et en formation, France, v. 29, p. 221-250, 2011.

7 Problem-basic learning
} 
imaginar um plano de curso geral, ou seja, o conteúdo a ser compartilhado. Mas, o plano de aula seria feito de forma individualizada, de maneira que atendesse tanto a ideia da criança com conhecimentos mais avançados como a iniciante, ou aquela que apresenta diferentes maneira de aprender. Por isso as atividades seriam organizadas por temas e níveis de aprofundamento, em grupos e individualmente. Outro ponto elementar foram as práticas abordadas de forma interdisciplinar.

O tempo pensado para as atividades e o acompanhamento, carga horária, foi de duas horas semanais para cada turma. Foi consenso a necessidade de um tempo que permitisse trabalhar o conteúdo, por intermédio dos projetos, em extensão e profundidade. Ficou acordado que o curso duraria um semestre letivo e aconteceria durante o contra turno das atividades escolares.

O quinto polo foi a estrutura de organização e recursos didáticos. O espaço maker usufrui da estrutura universitária pré-existente no LPPI e salas apropriadas para atividades em grupo ou individuais. Nessa etapa de trabalho, o espaço maker não possui financiamento por órgãos de fomento e isso cria desafios para aquisição de materiais de consumo para desenvolvimento de atividades que demandam materiais como o arduino ou filamentos para impressora $3 \mathrm{~d}$. Problema ainda em discussão o que demandou a busca por alternativas. Mesmo assim, foi possível dar início ao projeto, pois foram alocados 10 netebooks de outro órgão universitário e do LPPI foram emprestados 10 netebooks, 5 kits lego mindstorms, lousa digital e a própria estrutura do Departamento de Educação.

Após toda a discussão sobre estrutura, organização, conteúdo a equipe avançou a discussão para as competências a serem desenvolvidas pelos estudantes. Alguns pontos já haviam se estruturado naturalmente a partir da discussão da abordagem pedagógica, como por exemplo, valorizar as competências individuais sem perder de vista o desenvolvimento de habilidades em outras áreas ou a interdisciplinaridade. Pensar a proposta sem conhecer o público alvo foi um problema elencado a todo momento pela equipe. Foi reafirmado a necessidade da avaliação diagnóstica e da avaliação formativa para acompanhar a aprendizagem dos estudantes. Mas de qual competências falamos? Quais competências desenvolver? Foi então que as competências educacionais apresentadas pela Sociedade brasileira de Computação (SBC) tomaram importância no grupo. Mais uma vez trazendo uma discussão acirrada, pois as competências propostas pela SBC, com base na Base Nacional Comum Curricular (BNCC), são audaciosas para a realidade da educação básica.

Quando da sistematização, alguns vazios se apresentaram em relação ao acompanhamento dos estudantes, seja individualmente ou em grupo. Pensamos em três tipos de acompanhamento: a tutoria que visa acompanhar o desenvolvimento e necessidade de um grupo, o que poderíamos 
chamar de acompanhamento pedagógico e outros dois acompanhamentos voltado para o conteúdo, um de forma individualizada e outro geral. Então optou-se pela construção coletiva dos planos de atividades mobilizadoras e diálogo sobre os conteúdos em consonância com o acompanhamento feito pelo tutor. Seria o momento da reunião pedagógica para realizar o acompanhamento de cada estudante em uma lógica de avaliação formativa como retroalimentação para planificação das atividades, entendendo a necessidade de aprendizagem de cada criança e organizando o trabalho por grupos de interesse. Podemos inferir aqui que o grupo teve consciência da própria necessidade do trabalho em equipe para realizar uma proposta de ensino-aprendizagem maker.

Por fim o grupo se atentou à necessidade da divulgação para a inscrição e da inscrição propriamente dita. Alguns questionamentos foram levantados, mas não foram finalizadas as discussões por entenderem que este seria um problema a ser tratado mais a frente, as questões levantadas foram: Como será feita a seleção? Por ordem de inscrição? Sorteio? Onde seria feita a inscrição? Online? Presencial?

A proposta pedagógica desenhada pelo grupo consistiu em abordar o conteúdo a partir da aprendizagem baseada em projeto e a aprendizagem baseada em problemas. A PBL elege um problema como ponto de partida para abordar o conteúdo. É o estudante que deve trazer temas e junto com seu grupo e apoio do seu tutor problematizar, discutir e pesquisar em grupo possíveis soluções para tal. Os estudantes exercem em rodízio os papéis de coordenador e secretário, para que as responsabilidades sejam compartilhadas (BORGES et al., 2014). Esta metodologia agrega a proposta do espaço maker, pois parte da elaboração do cenário ou contexto problemático - que no nosso caso será um projeto e o grupo irá discutir o problema- para formular questões de aprendizagem, dúvidas e conceitos importantes, seguida por um estudo individualizado e compartilhamento dos conhecimentos adquiridos.

A aprendizagem baseada em projetos (ABP) possibilita que o ensino se aproxime das mudanças e avanços tecnológicos. Esta metodologia permite que o professor organize estratégias para interação dos estudantes, situações que estimulem a troca e o estabelecimento de uma visão crítica e da própria elaboração do projeto em etapas, o que permitirá ao estudante passar por cada um dos conteúdos propostos, e a equipe a buscar aprofundar seu conhecimento (VIEIRA; MARTINS, 2018).

Pensando na complexidade de cada projeto, pode ser feita uma leitura da proposta de Jerome Bruner (1985) que nos apresentou o método da aprendizagem por descoberta. Este modelo parte de um problema e a busca de alternativas que levem à solução em um currículo em espiral, ou seja, diferentes níveis de aprendizagem e aprofundamento do tema que ele chamou de 
“andaimar". O estudante a partir de seus conhecimentos prévios reorganiza as novas informações e produz novos conceitos ou proposições.

O objetivo de abordar o conteúdo desta maneira se inscreve na proposta maker, ou seja, Do It Yourself, e para que os estudantes possam construir, consertar ou criar seus próprios objetos eles devem partir de um projeto inicial e desenvolvê-lo procurando olhar a proposta de vários ângulos. Para isso o estudante terá o apoio da equipe multidisciplinar com conhecimentos na área de arduino, jogos em scratch, desenho em $2 \mathrm{~d}$ e $3 \mathrm{~d}$, aplicativos de edição de texto e planilhas, entre outros. A proposta abrangeu aspectos técnicos, estruturais e didático-pedagógicos para que o projeto pedagógico do curso fosse elaborado. O planejamento do curso foi elaborado com estratégias que permitem inserir particularidades e interesses de cada estudante, projeto e grupo. Abriu-se aqui o campo para um novo desafio, a construção coletiva do plano de curso. O coletivo traz a noção de pertencimento e concepção da equipe, por um lado esse aspecto é enriquecedor e diferencial, mas por outro traz desafios tais como: acompanhamento do estudante, interação, número de estudantes por educadores, construção coletiva, respeito à individualidade e ao coletivo, trabalho coordenado, entre outros. Assim, será no curso da atividade, ou seja, na implementação e execução, que será possível avaliar e ajustar as premissas, ações e resultados esperados.

\section{Considerações finais}

Neste estudo buscamos sistematizar o trabalho e as discussões realizadas por pesquisadores e estudantes ao longo de dez meses com vistas a implementar uma proposta pedagógica interdisciplinar e criativa, voltada para as tecnologias da informação aplicadas à educação fundamental. Trata-se de construção coletiva com presença ativa na concepção de um processo formativo em todos os seus aspectos. Tal processo formativo está em análise na forma de um curso que teve início em setembro de 2019, com 20 estudantes do fundamental 1 e 20 do fundamental 2.

Como todo processo de construção coletiva, nem sempre as escolhas foram as unânimes e sim as passíveis de serem executadas no momento. Um exemplo disso foram as discussões sobre a segregação de participantes por faixa etária, ponto de insegurança entre os futuros mediadores das atividades de mobilização, visto se tratar de uma quebra de paradigma em relação à educação escolar vigente.

As discussões se pautaram na utopia da "escola dos sonhos", como instância formativa que agregasse diferentes sujeitos e competências, mas a dificuldade de transpor para o real a atividade, da teoria para o agir do educador, foi latente. A etapa de discussão do conteúdo com base na 
proposta da SBC foi um exemplo desta dificuldade. A maioria da equipe, com conhecimento de tecnologias, via as atividades de forma complexa e um engessamento do lúdico, preso a uma matriz pré-elaborada. A atividade de transposição foi realizada com o intuito de se estabelecer uma lógica entre o lúdico e um conteúdo parcialmente estruturado, desvelando a necessidade de elaborar uma matriz como uma espinha dorsal que pudesse agregar o ideário pedagógico decorrente do marco teórico sustentado por Perrenoud, Bruner e Vygotsky.

A equipe procurou abordar a construção da proposta em seus aspectos técnicos, estruturais e didático pedagógico. Como projeto de intervenção, a proposta elaborada no projeto Maker apresenta pontos vulneráveis e potencialidades. Esses serão monitorados e avaliados, e fazem parte de outra etapa desta pesquisa que se encontra em execução, no momento este artigo reúne análises das primeiras etapas do projeto que se consolidará ao longo da implementação das atividades propostas.

\section{Referências}

BAUMAN, Zygmunt. Modernidade Líquida. 1ª ed. Rio de Janeiro: J. Zahar Ed., 2001

BRASIL. Ministério da Educação. Lei no. 9.394, de 20 de dezembro de 1996. Estabelece as diretrizes e bases da educação nacional. Diário Oficial [da] República Federativa do Brasil, Brasília, DF, 23 dez. 1996.

BRASIL. Ministério da Educação. Secretaria de Educação Básica. Base Nacional Comum Curricular. 3a versão revista. Brasília, DF: MEC/SEB, 2017. Disponível em: http://basenacionalcomum.mec.gov.br/images/BNCC_20dez_site.pdf. Acesso em 20 out. 2018.

Bruner, J. Vygotsky: a historical and conceptual perspective. In Wertsch, J. V. (Ed.) Culture, Communication and Cognition: Vigotskian Perspectives. Cambridge: Cambridge University Press. 1985.

CARLOS, Philippe de. Le savoir historique à l'épreuve des représentations sociales: l'exemple de la préhistoire et de Cro-Magnon chez les élèves de cycle 3 . Tese de Doutorado. Sciences de l'éducation, Université de Cergy-Pontoise, França. 2015.

BORGES, M.C et al. Aprendizado baseado em problemas. Medicina, (Online), Ribeirão Preto. v. 47, n. 3, p. 301-307, 2014.

CHEVALLARD, Yves. Les processus de transposition didactique et leur théorisation, Contribution. In: ARSAC G. et al. (éds), La transposition didactique à l'épreuve. La Pensée sauvage, Grenoble, p. 135-180, 1994.

CHEVAlLARD, Yves. Pourquoi la transposition didactique? Actes du Séminaire de didactique et de pédagogie des mathématiques de l'IMAG, Université scientifique et médicale de Grenoble. p. 167-194, 1982. 
ECDL Foundation. La falacia del "nativo digital" ¿Por qué los jóvenes necesitan desarrollar sus habilidades digitales? EDUTEKA. Universidad Veracruzana. Documento elaborado por la

ECDL Foundation y publicado en el portal Eduteka con autorización de ICDL Colombia. Acessado em: 29 de novembro de 2017. Disponível em: https://www.uv.mx/blogs/sea/2016/04/26/la-falacia-del-nativo-digital-por-que-los-jovenesnecesitan-desarrollar-sus-habilidades-digitales/

IMD. International institute for management development. World competitiveness digital ranking 2019. World Competitiveness Center. Country profile, 2019. Acessado em 10 de janeiro de 2019. Disponível em; https://www.imd.org/wcc/world-competitiveness-centerrankings/countries-profiles/

LAKATOS, Eva Maria, MARCONI, Marina de Andrade. Fundamentos de metodologia científica - 5. ed. - São Paulo : Atlas 2003.

MÓNICO, L. et al. A Observação Participante enquanto metodologia de investigação qualitativa. CIAIQ : Atas - Investigação Qualitativa em Ciências Sociais 2017, v. 3, 2017. Disponível em: < https://proceedings.ciaiq.org/index.php/ciaiq2017/article/view/1447>. Acessado em 20 de agosto de 2019.

MORAN, J. Como transformar nossas escolas: novas formas de ensinar a alunos sempre conectados. In: CARVALHO, M. (Org). Educação 3.0: Novas perspectivas para o Ensino. Porto Alegre, Sinepe/RS/Unisinos, 2017.

PERRENOUD, Philippe. Construir as Competências desde a Escola. Porto Alegre: Artmed Editora, 1999.

PERRENOUD, Philippe et al. As Competências para ensinar no século XXI: a formação dos professores e o desafio da avaliação. Porto Alegre: Artmed, 2002.

PRESTES, Zoia Ribeiro. Quando não é quase a mesma coisa: análise de traduções de Lev Semionovitch Vigotski no Brasil-repercussões no campo educacional. Programa de PósGraduação em Educação, Universidade de Brasília, 2010.

RICARDO, Elio Carlos. A discussion about learning competences: problems and alternatives. Cadernos de pesquisa, São Paulo, v. 40, n. 140, p. 605-628, maio/ago. 2010.

SBC. Sociedade Brasileira de Computação. Diretrizes para ensino de Computação na Educação Básica. Ensino de Computação na Educação Básica. Sociedade Brasileira de Computação. Disponível em: http://www.sbc.org.br/documentos-da-sbc/send/203-educacao-basica/1220bncc- em-itinerario-informativo-computacao-2. Acessado em 8 de março de 2019.

VIEIRA, Estela Aparecida Oliveira; MARTINS, Ronei Ximenes. Formação do agir docente e o uso das metodologias ativas apoiadas nas tecnologias digitais. In: IV Congresso de Inovação e Metodologias no Ensino Superior. Belo Horizonte. 2018. Disponível em: $<$ https://congressos.ufmg.br/index.php/congressogiz/IVCIM/paper/viewPaper/871>. Acessado em 4 junho de 2019. 
VIGOTSKY, L.S., e LURIA, A.R. Estudos sobre a História do Comportamento: Símios, Homem Primitivo e Criança. Porto Alegre: Artes Médicas, 1996.

Recebido em: 06 fev. 2020/ Aprovado em: 25 jun. 2020

\section{$\underline{\text { Cite como }}$}

\section{(ABNT NBR 6023:2018)}

VIEIRA, Estela Aparecida Oliveira; MARTINS, Ronei Ximenes. Estudo exploratório para implementação de um espaço maker. Dialogia, São Paulo, n. 35, p. 245-262, maio/ago. 2020. Disponível em: https://doi.org/10.5585/dialogia.n35.16563.

\section{American Psychological Association (APA)}

Vieira, E. A. P., \& Martins, R. X. (2020, maio/ago.). Estudo exploratório para implementação de um espaço maker. Dialogia, São Paulo, 35, p. 245-262.

https://doi.org/10.5585/dialogia.n35.16563. 